\title{
Dossier
}

\section{Laberintos de la era del liberalismo económico}

\author{
Maribel De La Cruz Vergara, Dra \\ Profesora Investigadora \\ Programa de Historia \\ Universidad de Cartagena
}

\section{Presentación}

La apreciación de los procesos históricos pasados o del pasado reciente los abstraemos de acuerdo con nuestros intereses de investigación, la historia lo es por sí misma indistintamente de las interpretaciones que los estudiosos deseamos realizar de ella, de tal manera que es un asunto metodológico priorizar o dividir la historia en distintos campos, tal división la que en otra hora ha sido objeto de debates, está en el hecho de que ante la complejidad de abordar la historia desde todos sus ángulos, priorizamos uno de ellos en un intento de acoplarnos al movimiento del tiempo actual.

Así los estudios en historia económica, que lo son en la medida en que privilegian esta variable, han pasado por una relativa decadencia, sobre todo en Colombia, aunque en la actualidad y debido a la intervención de historiadores y economistas que se han especializado en esta área, ha retomado cierto dinamismo lo que ha permitido ciertas reinterpretaciones y aporte de estudios cuantitativos complementarios a las investigaciones de las denominada historia social, política y cultural. Entonces la importancia radica en la posibilidad de dar diferentes miradas a la realidad histórica.

De tal manera, que en este caso el dossier que presentamos sobre los Laberintos de la era del liberalismo económico nos invita a una lectura en el tiempo y el espacio de diferentes investigaciones en donde la teoría económica liberal se manifiesta desde

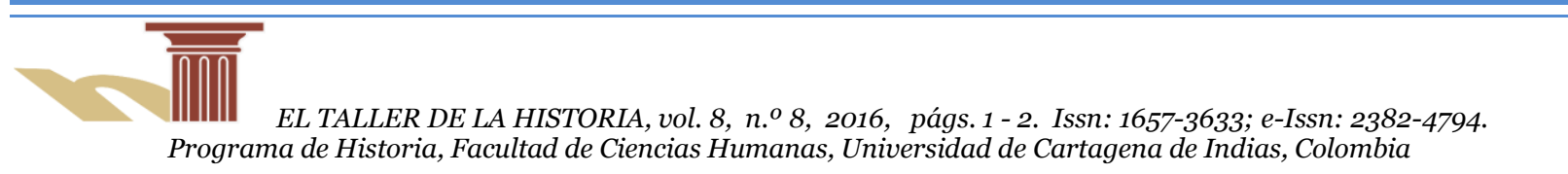


Presentación

diferentes aspectos y encarada en variadas políticas y acciones que han perfilado el trascurrir de la historia Latinoamérica, investigaciones que fueron socializadas en el V Seminario Internacional de Historia Económica.

Así, Javier Kraselsky, nos invita a la reflexión sobre los consulados de comercio, con el texto El consulado de comercio de Buenos Aires y sus redes económicas y políticas: Las diputaciones de Potosí y Montevideo 1795-1812 en donde devela la relación entre la Junta de Gobierno de Buenos Aires y los comerciantes de las diputaciones de Potosí y Montevideo, recalcando el derrumbe de las estructuras monárquicas y la conformación de los Estados nacionales.

Christianne Silva, por su parte nos presenta su investigación sobre La paradoja del liberalismo y la deuda de los Estados liberales, en relación con la abolición de la esclavitud, en la que sostiene que esta política tuteló el derecho patrimonial de los propietarios esclavista en detrimento de los esclavizados.

En el campo de las relaciones laborales y educativas Oscar Flores Torres y Magda Yadira Torres en su trabajo Oposición empresarial a las reformas laborales y educativas en México: el caso de Monterrey, 1962 - 1972, plantean las contradicciones entre el gobierno de Lázaro Cárdenas, las que condujeron a un movimiento conservador empresarial y religioso anticardenista, cuyo epicentro fue la ciudad de Monterrey. En un análisis comparativo temporal entre 1962 y 1968-1971, presenta la gestación de otro movimiento contra las demandas de apertura en la Educación Superior. 